\title{
Using digital technologies in inclusive education for preschool children
}

\author{
Indira Ismailova* \\ Moscow Pedagogical State University, Moscow, Russian Federation
}

\begin{abstract}
The article reveals the features and conditions of digital technologies in the inclusive education of preschool children with different nosologies. The very concepts used by modern teachers of preschool educational organizations are disclosed. Data on the role of parents in the digital education space and the peculiarities of working with them on the use of these technologies in a distance form are presented. Joint actions of teachers and parents in the preschool educational organization and separate parents' actions only on the organization of work on this or that digital platform and their application in the education of preschool children are shown. The tools and technologies used in preschool educational organizations by different professionals are reflected. The requirements for the organization of the child's workplace during the use of digital technology in preschool educational organizations and at home are disclosed in detail.
\end{abstract}

\section{Introduction}

In today's society, one can observe the rapid development of digital technology on many fronts. This process also affects the education system. New technologies are changing the modern education system, expanding the boundaries of research in the whole system of lifelong learning. The use of digital technologies in the sciences and the education system in the educational process makes them digital [1]. Different terms denote the intersection of information technology, different sciences, and education. Such plurality of terms is due, according to E.Yu. Zhuravleva, "historical, political, disciplinary, and educational contexts" [2, p. 92]. Digitalization of public life is taking place in many areas of life, including science and education. And people are now forced to adapt to the digital world. Academician V.L. Makarov draws attention to the fact that life in the digital world contributes to the change of many things, including ethical perceptions, social norms [see 3, p. 147]. In this paper, we are interested in using digital technologies in the inclusive education of preschool children.

Education for pre-school children is a mass process making it possible to carry out the education and development of all children of that age, without exception, regardless of their individual characteristics, academic achievements, mother tongue, culture, and mental and physical abilities. If we study the designated problem in the context of social justice, we can argue that in a democratic and free state, the interests of personal development of any social

\footnotetext{
${ }^{*}$ Corresponding author: ismai-indira@ yandex.ru
} 
group should be taken into account [4, p. 522]. At the same time, the necessary conditions for children's personal development should be perceived as a high value.

The introduction of inclusive education provides further humanization of education, recognizing the rights of persons with disabilities to accessible and quality education, the formation of a professional teaching community of a new type [5]. Such measures meet the principles of sustainable development of society, humanism, and social justice, which require creating conditions in society for the personal development of representatives of all social groups, including children with disabilities [6, p. 448].

The pedagogical sphere emphasizes the crucial role, place, and functions of the teacher in society and raises the demands and social expectations towards him/her. In addition, social rehabilitation should be aimed at involving and preparing the child with disabilities for a full and productive social life through specially organized training, education, and the creation of optimal conditions for this [7].

\section{Study methodology}

The object of the study is the process of digital education of preschool children with disabilities. This is a fairly broad category of children, including children with mental and sensory disabilities, autism spectrum disorders, mental retardation, speech pathology, cerebral palsy, etc. All these children have long been included in the general preschool system.

Methods and means of teaching children with disabilities do not actually differ from the norm, except for certain, specific methods, focused on ways of perceiving information display or the use of flat images on screens does not give the desired result. It is necessary or even obligatory for them to use verbal accompaniment of visually shown information. This is the task of determining the specifics of inclusion in education as a special stage of its reform in the direction of the implementation of integrative potential in relation to all categories of students [8].

Recently, scholars have been using the term e-inclusion, which is interpreted as the phenomenon of using digital technology to break down all barriers and include people with disabilities in a more active social life [9].

The specifics of children with disabilities, and among them there are children with emotional-volitional disorders, particularly with ASD, the essence of which is that they can not communicate directly or contact people, even with family and friends. Still, with the help of digital technology, they easily communicate. Therefore, this way of working for this category of children is a godsend. But still, certain conditions and requirements for the use of digital technology for all children with disabilities must be respected. Each category of children with disabilities has its own specific perception of the world and digital technologies. Therefore, educators need to be more careful when using them $[5,8,9]$.

There is also the possibility of using other computer programs for presenting material or organizing homework. For example, in Adobe, you can attach files for downloading didactic material. The letter may also contain links to material on the Internet. If a link to a specific video sequence is used, you should specify the time period of the recommended video. It is helpful to use various developmental online games on sites such as Mersibo as part of your homework. The letter should also contain a personal message to the caregiver. It is convenient to use bright animated pictures of encouraging characters, as a preschool child cannot read [5].

Even though the child is included in the preschool education system, teachers and specialists often face the absence of children with disabilities in the preschool educational organization (POE) due to regular rehabilitation courses prescribed by doctors in sanatorium 
conditions. Such regular interruptions adversely affect the results of corrective and pedagogical impact on the child with disabilities.

Creating a barrier-free environment together with the parents of the pupils to receive a quality education, equal starting opportunities, prevention of autism of the child in case of forced long-term hospitalization is possible through the use of digital distance learning technologies.

What is the digitalization of education? It is the use of digital technologies (computers, gadgets, phones, Internet) for education through the use of WhatsApp, Skype, Telegram, Zoom, Messenger, and other technologies, that is, social networks available jointly to parent and teacher, transfer to the parent information on the intermediate result through photos, links to videos, documents, presentations, actually it is the use of digital achievements of humanity [5]. Renowned Russian researcher A.Yu. Volodin rightly believes that the digital transition in modern sciences and in the whole system of education can be considered to have taken place $[10$, p. 5].

\section{Results of the study}

Digital technologies are also understood as educational technologies implemented mainly using remote information and telecommunication networks with indirect (at a distance) interaction between students and teaching staff. Abbott, in an article on the use of digital technologies in the learning process of persons with disabilities, showed that there are several directions of their use: to train skills, to provide feasible assistance in education, and the third direction for the empowerment of persons with disabilities [9]. Our article deals with the second use of digital technology - helping children get an education.

Due to the active development of digital technology, today, a special learning environment allows a teacher to organize an educational process, which is not inferior in its didactic capabilities to the traditional, and in many ways superior to it due to not only a purely individual approach to the student with disabilities but also the active inclusion of the family in the corrective and developmental process [7]. If we consider the social aspect of this problem, we note that creating all kinds of conditions for the disclosure of personal potential is an essential requirement of the principle of social justice. This requirement applies to all social groups $[11$, p. 278]. Children with disabilities, of course, require special attention in this regard.

Living in a world of information technology, parents give a greater role in the all-around development of gadgets, assuming that if a child "well know" a computer or tablet that actually performs some manipulations with them, then he has a fairly versatile idea of the world around him. There are many more examples of the peculiarities of raising a child with disabilities in a family. However, the feature of the preschool education system is that when a child enters a preschool educational establishment, the staff and teachers "lead by the hand" not only the child but also the family group for the entire period of preschool childhood. Where an adult is not "above the child", not "next to the child", but "together with the child", any organized educational activity will bring the very expected results [5].

When a child with a disability enters a pre-school educational organization, his or her parents are consulted about the use of digital technology in kindergarten and at home. As children with disabilities are often ill, they miss visits to preschool educational institutions. Therefore, parents need to schedule the mode, dosage, and organization of the use of gadgets, computers, TV in each case. It can be said that in the first month of visiting pre-school centers, parents go through a period of adaptation to their new role - parent-friend-helpermentor (tutor). This is because teachers strive to equip the parent with methods and techniques of work with the child in a sufficiently short time to ensure a successful joint work by the time of the expected long-term absence of the child with disabilities. 
After preventive work with parents, the teacher introduces them to the aids they plan to use in corrective and developmental work with their child, explains the possibilities of using them in certain tasks. Not out of old work habits, but so that parents could independently live this moment and understand what the game is in the classroom, the tutor plays with mom or dad those games that parents have already learned "in theory", introduces various surprises, game techniques. The main goal of this stage is to teach parents to play with their children so that the young children will be interested in the joint activities that the parent in the family will offer in the future on the tutor's instructions. Further show that the "game" in the computer or tablet is not just for playing, but that each game carries a specific goal to achieve. The importance of this skill is impossible to overestimate because every parent would probably want to be interesting, necessary, important for their child, not only about vital needs.

During the following time, the teacher can invite parents to a class where the parent, being a direct participant in the educational process, can demonstrate the knowledge gained earlier in the consultations.

The family of a child with disabilities must have a computer or laptop connected to the Internet, providing sufficient Internet speed for online communication, to organize a digital learning space. Various gadgets can be used for this purpose, such as a tablet or smartphone, but the screen size must be large enough and convenient for the child to perceive the image. They should also be equipped with a fixation device for fixing in various positions. Parents ensure that they have an email address, register for online communication by arrangement with the teacher. In agreement with the teacher, parents provide "on the other side of the screen" the availability of didactic aids.

There are certain workspace requirements when using any digital technology. When arranging a child's workplace for computer training, it is important to consider the following fundamental requirements. The furniture (table and chair) should be sized according to the child's height. The horizontal surface of the monitor table must be adjustable in height in a smooth, easy, and reliable manner. The screen's distance from the front edge of the table is $60-70 \mathrm{~cm}$ so that the required visual distance (from the eyes to the monitor screen) will be maintained. The keyboard table surface should have a smooth and easy to change tilt angle with secure locking or a fixed keyboard tilt angle to the horizontal $\left(7-15^{\circ}\right)$. The mouse sits at the same height as the keyboard, conveniently for both a parent and a child.

A sturdy, comfortable chair with adjustable height is best. The height of the chair should be adjusted so that the knees are in a slightly bent position and the feet are on the floor. The back of the chair should support the back (especially the lumbar region). Using the instructions for the chair, the parent should adjust the position of the back so that it corresponds to the natural position of the child's body. You may need to raise the seat so your forearms and hands are at the correct angle to the keyboard. If your child's feet do not reach the floor, you can use a footrest with adjustable height and inclination. You can also reduce the height of your desk so you don't have to resort to using a footrest. Alternatively, it is possible to use a table with a keyboard tray underneath the main work surface.

The monitor should be mounted so that the top of the screen is slightly below eye level when the child sits in front of the keyboard. The optimum distance from your eyes to the screen must be chosen by yourself. However, a minimum distance of $60 \mathrm{~cm}$ is recommended. Glare and reflections on the screen from artificial and natural lighting should be minimized [5].

It should be understood that equipping the workplace of a child with disabilities with various technical aids to partially or fully compensate for limitations related to physical, sensory, or neuropsychiatric disabilities will provide the child with comfortable access to the Internet. 
Before organizing educational activities online, the teacher should practice the main stages of organized educational activities to assimilate the system of interaction.

\section{Discussion of results}

The task of parents is to strengthen the child's confidence in his/her abilities, to support the child's desire to learn new things, and to be sure to show interest in the learning process.

Also, during the period of children's computer training, the function of the pupil's motor apparatus (coordination of fine motor skills of the hands) is the most significant. The positive impact of physical exercise is also expressed in the development of children's cheerfulness, optimism, activity, concentration, self-confidence. It is also essential that the exercises do not cause fatigue and overexcitement in the child.

While the child attends kindergarten, educators can enter homework offline and via email into the learning system. In Adobe you can attach files for downloading didactic material. The letter may also contain links to material on the Internet. If a link to a specific video sequence is used, you should specify the time period of the recommended video. It is helpful to use various developmental online games on sites such as Mersibo as part of your homework. The letter should also contain a personal message to the caregiver. Here it is convenient to use bright animated pictures of encouragement, as a preschool child can't read.

\section{Conclusion}

Thus, having analyzed the peculiarities and conditions of applying digital technologies in a preschool educational organization, we can say that they can be successfully used for the education of children with disabilities. Homework can be entered into the learning system both offline and digitally. Organized educational activities online with the tutor - continuation of corrective and developmental work on the individual route of the pupil. It should correspond as closely as possible to the preschool session, with all the load standards for the pupil. Then the main condition for success in the advancement of a child with disabilities in corrective and developmental work will be a properly organized, leading role of the parent. Comprehensive support of parents in mastering and fixing new knowledge and skills of pupils with disabilities creates the prerequisites for children to achieve high educational results, maximum development of their socially important competencies, including adequate self-realization in interaction with the outside world.

\section{References}

1. Philosophy of the digital world. PhilosophyStorm.org >filosofiya-tsifrovogo-mira

2. E. Yu. Zhuravleva, Questions of Philosophy 5, 91 (2011)

3. G.M. Birzhenyuk, Sociological researches 1, 146 (2018)

4. N.O. Ismailov, Law and Politics 4, 521 (2014)

5. I.S. Ismailova, Priority areas for the development of science and education, 113 (2019)

6. N.O. Ismailov, National Security 3, 445 (2014)

7. I.S. Ismailova, T.I. Oleshko, O.V. Belous, I.F. Igropulo, International Journal of Innovative Technology and Exploring Engineering 8(9), 1395 (2019)

8. A.Yu. Shemanov, Modern foreign psychology 5(3), 66 (2016)

9. C. Abbott, E-inclusion: Learning Difficulties and Digital Technologies, 32 (2007)

10. A.Yu. Volodin, Bulletin of Perm University, Series "History" 3(26), 5 (2014) 
11. N.O. Ismailov, Politics and Society 3, 277 (2014) 